\title{
Studi Laboratorium Pengaruh Variasi Temperatur Pemanasan Arang Batok Kelapa Terhadap Thickening Time dan Free Water Semen Pemboran
}

\author{
Novrianti ${ }^{1}$, Mursyidah ${ }^{2}$, Teguh Prasetya Utama ${ }^{1}$ \\ ${ }^{1}$ Program Studi Teknik Perminyakan Universitas Islam Riau
}

\begin{abstract}
The cementing process can determine successful oil well when producing oil to the surface. Planning the time required for the cement suspension to achieve consistency of $100 \mathrm{UC}$ (unit of consistency) or thickening time and the maximum limit of water content used is the nature of cement slurry that affect the quality of cement. The addition of coconut shell charcoal with variation of heating temperature $400{ }^{\circ} \mathrm{C}, 500{ }^{\circ} \mathrm{C}, 600{ }^{\circ} \mathrm{C}, 700{ }^{\circ} \mathrm{C}, 800{ }^{\circ} \mathrm{C}, 900{ }^{\circ} \mathrm{C}$ to the basic cement was done in this study to determine the effect of heating temperature of coconut shell charcoal to thickening time and free water cement drilling. This experimental study uses an additive material derived from coconut shell charcoal. This experiment begins by preparing a cement sample with a coconut shell charcoal concentration of $1 \%$. The coconut shell charcoal used has different heating temperatures of $400{ }^{\circ} \mathrm{C}, 500{ }^{\circ} \mathrm{C}, 600{ }^{\circ} \mathrm{C}, 700{ }^{\circ} \mathrm{C}, 800{ }^{\circ} \mathrm{C}, 900{ }^{\circ} \mathrm{C}$. Suspense cement is made by mixing $\mathrm{G}$ grade cement, water, bentonite, $\mathrm{CaCl} 2$ and coconut shell charcoal. Thickening time test using atmospheric equipment consistometer and measuring cups used to determine the value of free water. The results showed that the thickening time and free water values were influenced by the heating temperature of coconut shell charcoal. The higher coconut shell charcoal temperature used in the cement suspension make thickening time of the cement suspension becomes shorter. The optimum heating temperature of coconut shell charcoal is $700{ }^{\circ} \mathrm{C}$ with thickening time of 1 hour 38 seconds 52 seconds and free water $1.2 \mathrm{~mL}$.
\end{abstract}

Keywords: Drilling cement, Thickening time, Free water, Coconut shell charcoal

Corresponding Author e-mail address: novrianti@eng.uir.ac.id

\section{PENDAHULUAN}

Proses penyemenan merupakan salah satu bagian yang sangat penting dalam pemboran migas. Kegagalan dalam penyemenan formasi merupakan kerugian yang sangat besar, baik secara materi maupun efisiensi waktu. Operasi penyemenan bertujuan untuk melekatkan casing pada dinding lubang sumur, melindungi casing dari masalah-masalah mekanis sewaktu operasi pemboran berlangsung (seperti getaran), melindungi casing dari fluida formasi yang bersifat korosi dan untuk sebagai pemisah antar lapisan formasi di belakang casing (Burgoyne, Adam T. Jr, 1986). Kualitas bubur semen harus disesuaikan dengan karakteristik formasi yang akan disemen sehingga dapat mengurangi masalah yang sering terjadi dalam operasi penyemenan. Sifat-sifat semen yang perlu diperhatikan ketika melakukan operasi penyemenan adalah sifat bubur semen. Sifat bubur semen tersebut antara lain adalah perbandingan air/semen, densitas bubur semen, sifat fluid loss, karakteristik aliran, thickening time.

Thickening time didefinisikan sebagai waktu yang diperlukan suspensi semen untuk mencapai konsistensi sebesar $100 \mathrm{UC}$ (unit of concistency). Konsistensi sebesar $100 \mathrm{UC}$ merupakan batasan bagi suspensi semen masih dapat dipompakan lagi menurut standart API. Meskipun API menetapkan 100 UC sebagai batas thickening time, namun biasanya 70 UC adalah kekentalan maksimum yang masih dapat dipompa. Dalam proses penyemenan biasanya untuk lebih aman digunakan waktu penyemenan $50 \%$ dari thickening time. Waktu pemompaan suspensi semen harus lebih kecil dari thickening time, 
bila waktu pemompaan suspensi semen lebih besar dari thickening time, suspensi semen akan mengeras terlebih dahulu sebelum mencapai target yang diinginkan.

Water cement ratio adalah perbandingan antara volume air dan semen yang dicampurkan untuk mendapatkan sifat-sifat bubur semen yang diinginkan. Air yang dicampurkan tidak boleh terlalu banyak ataupun kurang, karena akan mempengaruhi baik buruknya ikatan semen. Batasannya diberikan dalam bentuk kadar maksimum dan minimum air. Kadar minimum air adalah jumlah air yang dicampurkan tanpa menyebabkan konsistensi suspensi semen lebih dari 30 UC. Kadar air maksimum ditunjukkan oleh adanya kandungan air yang bebas (free water).

Dalam beberapa tahun terakhir upaya-upaya besar telah dilakukan untuk meningkatkan kualitas semen pemboran dengan tambahan material yang bersifat pozzolanik pada semen bersama - sama dengan tambahan bahan kimiawi pada campuran bubur semen. Arang batok kelapa memiliki kandungan kimia oksida silika $\left(\mathrm{SiO}_{2}\right)$, oksida besi $\left(\mathrm{Fe}_{2} \mathrm{O}_{3}\right)$, dan oksida aluminium $\left(\mathrm{Al}_{2} \mathrm{O}_{3}\right)$ dan bersifat pozzolan karena kandungan kimia silika dan aluminia pada arang batok bertemu dengan zat kapur dan air, akan membentuk masa yang padat dan ikatan yang keras dan tidak dapat terlarut kembali dalam air. Selain itu arang batok kelapa bersifat light weighting material yaitu additif yang dapat menurunkan densitas suspensi semen (Imam Pranadipta, 2010).

Menurut Hawley (1999) proses pemurnian arang terjadi pada temperatur $500{ }^{0} \mathrm{C}$. Kadar karbon meningkat mencapai 90\%. Namun pemanasan diatas temperatur $700{ }^{0} \mathrm{C}$, hanya menghasilkan gas hidrogen. Karbon aktif yang ada dalam arang batok kelapa bersifat adsorpsi, dapat mengurangi hilangnya cairan suspensi semen. Patcharin Worathanakul et al.(2009) menyimpulkan bahwa kadar silika dapat ditingkatkan dengan proses pemanasan.

Penelitian ini dilakukan di laboratorium untuk menentukan pengaruh additive arang batok kelapa dengan variasi temperatur pemanasan $400{ }^{0} \mathrm{C}, 500{ }^{0} \mathrm{C}, 600{ }^{0} \mathrm{C}, 700{ }^{0} \mathrm{C}, 800{ }^{0} \mathrm{C}, 900{ }^{0} \mathrm{C}$ terhadap nilai thickening time dan free water semen pemboran.

\section{METODE PENELITIAN}

Persiapan peralatan dan bahan pengujian merupakan proses awal yang dilakukan sebelum penelitian dimulai, dilanjutkan dengan pengujian basic cement slurry sesuai standard American Petroleum Institute, lalu menguji pengaruh penambahan arang batok kelapa yang dipanaskan dengan variasi temperatur pemanasan thickening time dan free water semen pemboran.

Bahan utama yang disiapkan sebelum melakukan penelitian adalah semen pemboran dengan klasifikasi API kelas G produksi PT. Holcim. Arang batok kelapa yang digunakan sebagai additive tambahan didapatkan dari Pabrik Arang Ipan Rumbai Pesisir, Pekanbaru sebanyak 25 kilogram arang batok kelapa. Komposisi kimia arang batok keapa dan sifat fisik arang batok kelapa yang digunakan terdapat pada tabel 1 dan tabel 2 . 
Tabel 1 Komposisi Kimia Arang Batok Kelapa

\begin{tabular}{cc}
\hline Unsur Kimia & Kandungan (\%) \\
\hline $\mathrm{MgO}$ & 2.5 \\
\hline $\mathrm{Al}_{2} \mathrm{O}_{3}$ & 1.2 \\
\hline $\mathrm{SiO}_{2}$ & 45.07 \\
\hline $\mathrm{P}_{2} \mathrm{O}_{5}$ & 9.77 \\
\hline $\mathrm{SO}_{3}$ & 3.12 \\
\hline $\mathrm{C}$ & 4.96 \\
\hline $\mathrm{K}_{2} \mathrm{O}$ & 6.59 \\
\hline $\mathrm{CaO}$ & 24.2 \\
\hline $\mathrm{Cr}_{2} \mathrm{O}_{3}$ & 0.27 \\
\hline $\mathrm{Fe}_{2} \mathrm{O}_{3}$ & 1.8 \\
\hline $\mathrm{CuO}_{\mathrm{ZnO}}$ & 0.27 \\
\hline $\mathrm{Rb} 2$ & 0.13 \\
\hline & 0.12 \\
\hline
\end{tabular}

Tabel 2 Sifat Fisik Karbon Batok Kelapa

\begin{tabular}{cc}
\hline Sifat Fisik & Keterangan \\
\hline Warna & Hitam \\
\hline Spesific Gravity & 1.12 \\
\hline Density & $0.208 \mathrm{gr} / \mathrm{cc}$ \\
\hline Ash Concentration & $10 \%$ \\
\hline Sifat Fisik & Keterangan \\
\hline Spesific Heat & $1 \mathrm{~J} /\left(\mathrm{g}^{\circ} \mathrm{C}\right)$ \\
\hline Thermal Conductivity & $0.2 \mathrm{~W} /(\mathrm{mK})$ \\
\hline Moisture Content & $4 \%$ \\
\hline
\end{tabular}

Arang batok kelapa yang telah ada, kemudian dihaluskan menggunakan blender dan disaring menggunakan sieve analisys dengan ukuran 200 mesh. Pemanasan arang batok kelapa dengan variasi temperatur pemanasan $400{ }^{\circ} \mathrm{C}, 500{ }^{\circ} \mathrm{C}, 600{ }^{\circ} \mathrm{C}, 700{ }^{\circ} \mathrm{C}, 800{ }^{\circ} \mathrm{C}, 900{ }^{0} \mathrm{C}$ menggunakan oven furnace.

Pembuatan suspense semen dilakukan dengan cara mencampurkan semen, air, bentonie, Cacl2, dan $1 \%$ by weight on cement arang batok kelapa sawit dengan temperatur pemanasan yang berbeda - beda yaitu $400{ }^{\circ} \mathrm{C}, 500{ }^{\circ} \mathrm{C}, 600{ }^{0} \mathrm{C}, 700{ }^{\circ} \mathrm{C}, 800{ }^{\circ} \mathrm{C}$ dan $900{ }^{\circ} \mathrm{C}$. Suspense semen dibuat dengan cara memasukkan air terlebih dahulu ke dalam cement mixer. Menyalakan mixer dengan kecepatan rendah $(4000 \pm 200$ rpm) lalu memasukkan semen, additive dan arang batok kelapa, melanjutkan pengadukan dengan kecepatan tinggi $(1200 \pm 500 \mathrm{rpm})$ selama 10-15 menit. Terdapat 6 sample yang digunakan dalam penelitian ini seperti yang terdapat pada tabel 3. 
Tabel 3 Komposisi Sampel Semen

\begin{tabular}{ll}
\hline Sampel & Temperatur Pemanasan $\left({ }^{\circ} \mathrm{C}\right)$ \\
\hline S1 & SD $+1 \%$ arang batok kelapa temperatur pemanasan $400{ }^{\circ} \mathrm{C}$ \\
\hline S2 & SD $+1 \%$ arang batok kelapa temperatur pemanasan $500{ }^{\circ} \mathrm{C}$ \\
\hline S3 & SD $+1 \%$ arang batok kelapa temperatur pemanasan $600{ }^{\circ} \mathrm{C}$ \\
\hline S4 & SD $+1 \%$ arang batok kelapa temperatur pemanasan $700{ }^{\circ} \mathrm{C}$ \\
\hline S5 & SD $+1 \%$ arang batok kelapa temperatur pemanasan $800{ }^{\circ} \mathrm{C}$ \\
\hline S6 & SD $+1 \%$ arang batok kelapa temperatur pemanasan $900{ }^{\circ} \mathrm{C}$ \\
\hline
\end{tabular}

Setelah pembuatan suspensi semen selesai dilanjutkan dengan pengujian. Pengujian thickening time dilakuan dengan menggunakan alat atmospheric consistometer dengan temperatur $140^{\circ} \mathrm{F}\left(60{ }^{\circ} \mathrm{C}\right)$. Sedangkan Pengujian free water suspensi semen dilkaukan dengan menggunakan gelas ukur. Gelas ukur diisi dengan suspensi semen sebanyak $250 \mathrm{~mL}$, didiamkan selama 2 jam sehingga terjadi air bebas pada bagian atas gelas ukur dan volume air bebas yang dihasilkan merupakan free water.

\section{HASIL DAN PEMBAHASAN}

Pengaruh campuran $1 \%$ arang batok kelapa dengan variasi temperatur pemanasan $400{ }^{\circ} \mathrm{C} 500{ }^{\circ} \mathrm{C}, 600$ ${ }^{0} \mathrm{C}, 700{ }^{\circ} \mathrm{C}, 800{ }^{\circ} \mathrm{C}$ dan $900{ }^{\circ} \mathrm{C}$ terhadap thickening time dapat dilihat pada Tabel 4.

Tabel 4 Thickening Time arang batok kelapa variasi temperature Pemanasan

\begin{tabular}{cc}
\hline Temperatur pemanasan Arang batok kelapa $\left({ }^{\circ} \mathrm{C}\right)$ & Thickening Time \\
\hline Semen Dasar + Arang Batok Kelapa $400{ }^{\circ} \mathrm{C}$ & 1 jam 58 menit 42 detik \\
\hline Semen Dasar + Arang Batok Kelapa $500{ }^{\circ} \mathrm{C}$ & 1 jam 53 menit 30 detik \\
\hline Semen Dasar + Arang Batok Kelapa $600{ }^{\circ} \mathrm{C}$ & 1 jam 43 menit 06 detik \\
\hline Semen Dasar + Arang Batok Kelapa $700{ }^{\circ} \mathrm{C}$ & 1 jam 38 detik 52 detik \\
\hline Semen Dasar + Arang Batok Kelapa $800{ }^{\circ} \mathrm{C}$ & 1 jam 40 menit 53 detik \\
\hline Semen Dasar + Arang Batok Kelapa $900{ }^{\circ} \mathrm{C}$ & 1 jam 45 menit 36 detik \\
\hline
\end{tabular}

Berdasarkan table 4 maka semakin tinggi temperatur arang batok kelapa yang digunakan pada suspensi semen, semakin kental suspensi semen, sehingga menyebabkan waktu thickening time suspensi semen semakin singkat. Tetapi setelah melewati temperatur pemanasan $700{ }^{\circ} \mathrm{C}$ thickening time tidak menjadi semakin singkat melainkan semakin panjang. Hal ini mengidentifikasikan bahwa temperatur pemanasan $700{ }^{\circ} \mathrm{C}$ dengan nilai thickening time 1 jam 38 detik 52 detik merupakan temperatur optimum pemanasan arang batok kelapa. Di atas temperatur $700{ }^{\circ} \mathrm{C}$ suspensi semen yang ditambahkan arang batok kelapa menjadi encer dan menyebabkan thickening time semakin panjang. Hal ini menunjukkan, bahwa $\mathrm{SiO}_{2}$ yang ada dalam arang batok kelapa besifat menyerap air, sehingga suspensi semen menjadi kental.

Hasil Pengujian laboratorium pada gambar 1 memperlihatkan bahwa semakin tinggi temperatur pemanasan arang batok kelapa, nilai free water semakin kecil. Hal ini disebabkan adanya kandungan $\mathrm{SiO} 2$ di dalam arang batok kelapa yang berfungsi menyerap air, sehingga suspensi semen menjadi lebih kental. Adapun nilai free water pada temperatur pemanasan arang batok kelapa $400{ }^{\circ} \mathrm{C}$ adalah $2 \mathrm{~mL}$, temperatur pemanasan $500{ }^{\circ} \mathrm{C}$ adalah $1,8 \mathrm{ml}$, temperatur pemanasan $600{ }^{\circ} \mathrm{C}$ adalah $1,5 \mathrm{~mL}$, temperatur pemanasan $700{ }^{\circ} \mathrm{C}$ adalah $1,2 \mathrm{~mL}$, temperatur pemanasan $800{ }^{\circ} \mathrm{C}$ adalah $1,4 \mathrm{~mL}$ dan temperatur 
pemanasan $900{ }^{0} \mathrm{C}$ adalah 1,6 mL. Nilai free water semakin besar, setelah melewati temperatur pemanasan $700{ }^{\circ} \mathrm{C}$ sehingga dapat disimpulkan bahwa temperatur optimum karbon batok kelapa adalah $700{ }^{0} \mathrm{C}$.

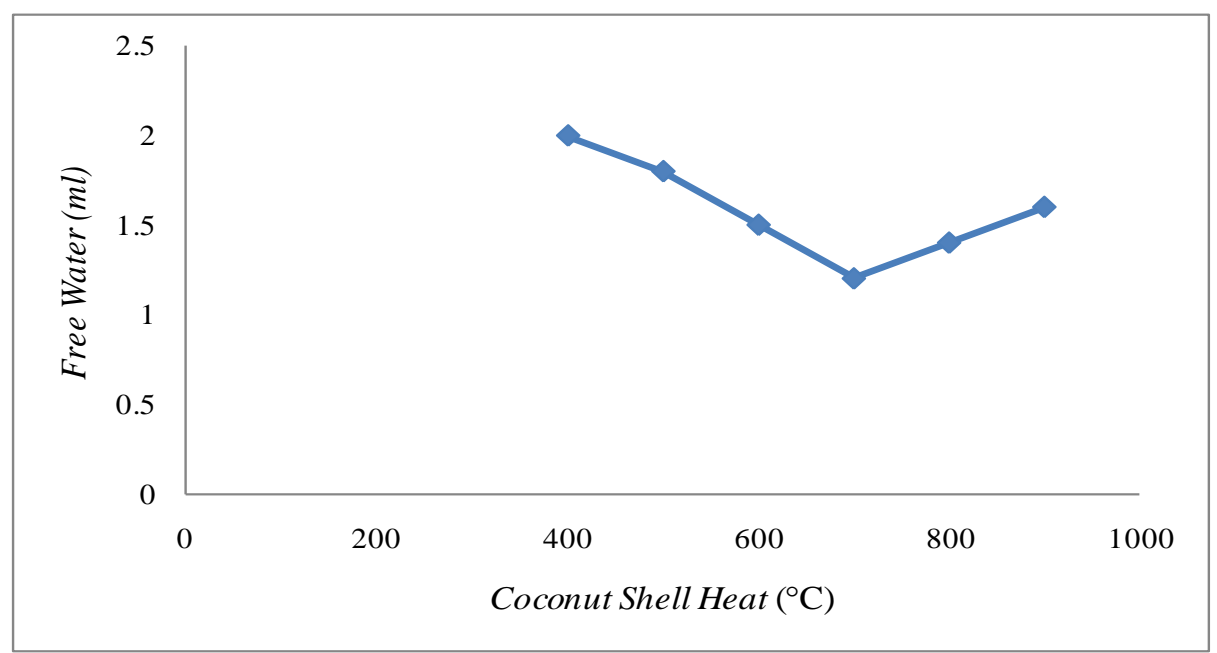

Gambar 1 Free Water

\section{KESIMPULAN}

1. Penambahan additive arang batok kelapa dengan variasi temperatur pemanasan berpengaruh terhadap nilai thickening time dan free water semen pemboran.

2. Nilai optimum thickening time yang diperoleh dengan menambahkan additive arang batok kelapa dengan variasi temperatur pemanasan adalah 1 jam 38 detik 52 detik pada temperatur pemanasan arang batok kelapa $700{ }^{\circ} \mathrm{C}$.

3. Nilai optimum free water yang diperoleh dengan menambahkan additive arang batok kelapa dengan variasi temperatur pemanasan adalah $1,2 \mathrm{~mL}$ pada temperatur pemanasan arang batok kelapa 700 ${ }^{0} \mathrm{C}$.

\section{DAFTAR PUSTAKA}

American Petroleum Institute. (2002). API Specification 10A Specification for well cements and Materials for Well Cementing (32rd Ed.). Washington, D.C., USA.

Buntoro, A. \& Rudi, R. (2001). The Effect of Neat Magnesium Oxide (MgO) As Expanding Additive with Burning Temperatur $1200^{\circ} \mathrm{C}$ And $1300^{\circ} \mathrm{C}$ On Cement Shear Bond Strength At High Pressure And Temperatur. Proceeding of The $5^{\text {th }}$ Inaga Annual Scientific Conference And Exhibition. Yogyakarta.

Burgoyne, Adam T. (1986). Jr. Applied Drilling Engineering. USA: SPE, 85-103.

Ershadi, V., et al. (2011). The effect of nanosilica on cement matrix permeability in oil well to decrease the pollution of receptive environment. Int. J. Environ. Sci. Develop 2: 128-132.

Hawley. (1999). The effect of heating on the manufracture of activated charcoal.

Irawan, Sony. (2011) Komposisi Kimia Arang Batok Kelapa dan Fly Ash, Laboratorium UTP, Malaysia.

Nelson, E. B. (1990). Well cementing. Newnes. 
Pranadipa, Imam. (2010). Utilization of Oil Palm Shell Charcoal As An Extender In Oil Well Cement. 34th Annual Convention and Exhibition, Indonesian Petroleum Association

Worathanakul, Patcharin., Payubnop, Wisaroot \& Muangpet, Akhapon. (2009). Characterization for Post-treatment Effect of Bagasse Ash for Silica Extraction. World Academy of Science, Engineering and Technology. 